\title{
Syndrome of cerebellar ataxia and hypogonadotrophic hypogonadism: evidence for pituitary gonadotrophin deficiency
}

\author{
A C K FOK, M C WONG, J S CHEAH \\ From the University Department of Medicine, Singapore General Hospital, Singapore
}

SUMMARY Familial cerebellar ataxia with hypogonadotrophic hypogonadism is a rare condition. Two affected siblings in a sibship of three were studied and found to have low plasma gonadotrophin levels. No rise in gonadotrophin levels was demonstrable after repeated stimulation with LHRH. The pattern of TSH and prolactin responses to TRH stimulation suggest hypothalamic dysfunction. The results clearly identify the cause of hypogonadism to be due to a defect in production or release of gonadotrophins by the pituitary gland and suggest that hypogonadism is part of a greater endocrine disturbance involving both the hypothalamus and pituitary.

The association of spino-cerebellar degeneration of the nervous system with endocrine dysfunction is well established. Holmes ${ }^{1}$ first described a family of eight siblings in whom four members with cerebellar ataxia were noted to be sexually undeveloped. Except for one report, ${ }^{2}$ the endocrine status of such patients has been poorly documented. We describe the investigations performed which establish the cause of hypogonadism to be due to a defect in the pituitary.

\section{Case report}

\section{Case 1}

An 18 year old Chinese male presented with unsteadiness of gait. His birth and developmental history were normal till the onset of ataxia at 8 years of age. He was the youngest of three siblings from a non-consanguineous marriage. On examination, he was found to be pre-pubertal. He was $166 \mathrm{~cm}$ in height and had eunuchoid proportions. He was sexually undeveloped with absent facial and pubic hair. The testicular volumes were $1 \mathrm{ml}$ bilaterally. There was gaze-dependent nystagmus, with limb and truncal ataxia and pendular knee jerks. Fundoscopy revealed peri-papillary degeneration with chorio-retinal atrophy. The optic discs were normal with high

Address for reprint requests: A C K Fok, M.MED, MRCP, University Department of Medicine, Singapore General Hospital, Singapore 0316, Republic of Singapore.

Received 5 July 1988 and in revised form 10 October 1988.

Accepted 17 October 1988 myopia and astigmatism. No sensory deficits or pyramidal release were detected. CT of the brain revealed uniform atrophy of the cerebellar hemispheres. The fourth ventricle was dilated consequent upon the atrophy (fig). The pituitary fossa, cervical spine and base of skull were normal. Conduction velocities over median, ulnar and common peroneal nerves were normal. The electrocardiogram and karyotype were normal.

\section{Endocrinological studies}

The results showed a hypogonadotrophic hypogonadism. (table) The LH and FSH responses to a $100 \mu \mathrm{g}$ dose of LHRH were subnormal. This was followed by twice-daily intramuscular injections of $100 \mu \mathrm{g}$ LHRH (Relefact $^{\mathrm{R}}$ Hoechst AG, Germany) for 7 days. A second LHRH stimulation was performed at the end of the 7 days under similar conditions. Gonadotrophin assays were quantified in duplicate by radio-immunoassay using commercial kits (Pharmacia Diagnostics AB, Uppsala Sweden).

\section{Case 2}

A 21 year old Chinese female (sister of Case 1) was seen for primary amenorrhoea and ataxia. Her birth and developmental history were normal till the onset of unsteadiness at 6 years of age. On examination she was found to be prepubertal with eunuchoid proportions. She was $156 \mathrm{~cm}$ in height with an upper to lower segment ratio of 0.85 , and an arm span of $169 \mathrm{~cm}$. The patient was sexually undeveloped with no secondary sexual hair or breast development. Gynaecological examination revealed a small vagina with clinically undetectable cervix, uterus and adnexal structures. There was limb and truncal ataxia with scanning speech, 


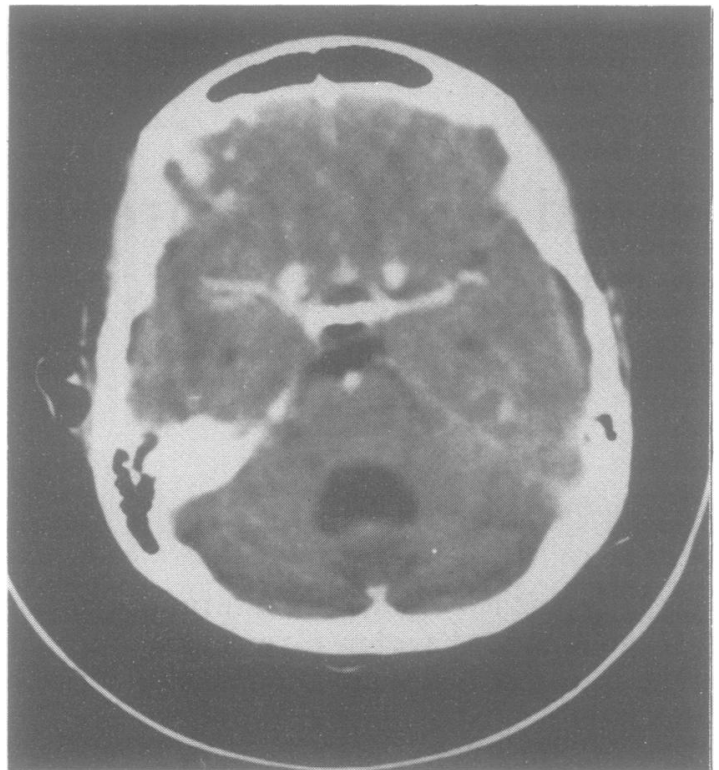

Figure CT scan of Case 1 showing dilatation of the fourth ventricle consequent upon cerebellar atrophy.

nystagmus and pendular knee jerks. Sensory deficits or pyramidal release were not detected. CT of the brain revealed bilateral cerebellar atrophy with a dilated fourth ventricle and a normal pituitary fossa. The karyotype was 46XX. Pelvic ultrasound revealed agenesis of the uterus and adnexal structures. Endocrinological studies revealed hypogonadotrophic hypogonadism. The 17-beta oestradiol was less than $11 \mathrm{pg} / \mathrm{ml}$ (normal 48-350) while the LH was less than $2 \mathrm{IU} / 1$ (normal 5-24) and the FSH 1.3 IU/1 (normal 4-12). The serum prolactin level was $6.7 \mathrm{ng} / \mathrm{dl}$ (normal 5-27.7).

\section{Discussion}

The heredo-familial ataxias are a heterogenous category of degenerative disorders involving the nervous system. ${ }^{3}$ There are several variants, of which Friedreich's ataxia ${ }^{4}$ is the most well known. A predominantly cerebellar form,${ }^{5}$ the type found in our patients, is another variant.

In 1907 Holmes $^{1}$ first reported an association between cerebellar ataxia and sexual undevelopment. It is now known that the ataxia-hypogonadism syndrome occurs in two forms. One is the association of ataxia with hypergonadotrophic hypogonadism, of which there are several reports. ${ }^{6-8}$ The most commonly identified cause of hypergonadotrophic hypogonadism appears to be Klinefelter's syndrome. ${ }^{78}$ The other variety associates cerebellar ataxia with a hypogonadotrophic form of hypogonadism. This has been reported by several authors ${ }^{9-12}$ who found low levels of urinary gonadotrophins in the cases studied, presumably from disease of the hypothalamus or pituitary.

Berciano ${ }^{2}$ provided the first evidence for a hypothalamic defect by demonstrating an increase in gonadotrophin levels after repeated stimulation with LHRH, pointing to a deficiency in hypothalamic stimulating factor.

The clinical features of our propositi are virtually identical to those decribed by Berciano. ${ }^{2}$ However, our results were dissimilar. The absence of a rise in $\mathrm{LH}$ and FSH after repetitive stimulation with LHRH points to a defect in pituitary production or secretion of gonadotrophins. The absence of lesions in the pituitary and hypothalamus on CT of the brain corroborates our postulation that the defect is a functional one rather than a structural one.

There is also evidence to suggest that the defect is not confined to the pituitary but involves the hypothalamus as well. The TSH and prolactin responses to TRH stimulation at 60 minutes are higher than those at 20 minutes (table). This pattern of responses is presumptive evidence of hypothalamic dysfunction.

There was impairment of $\mathrm{GH}$ release despite

Table Baseline hormonal profile and results of combined GnRH and TRH stimulation, insulin tolerance tests

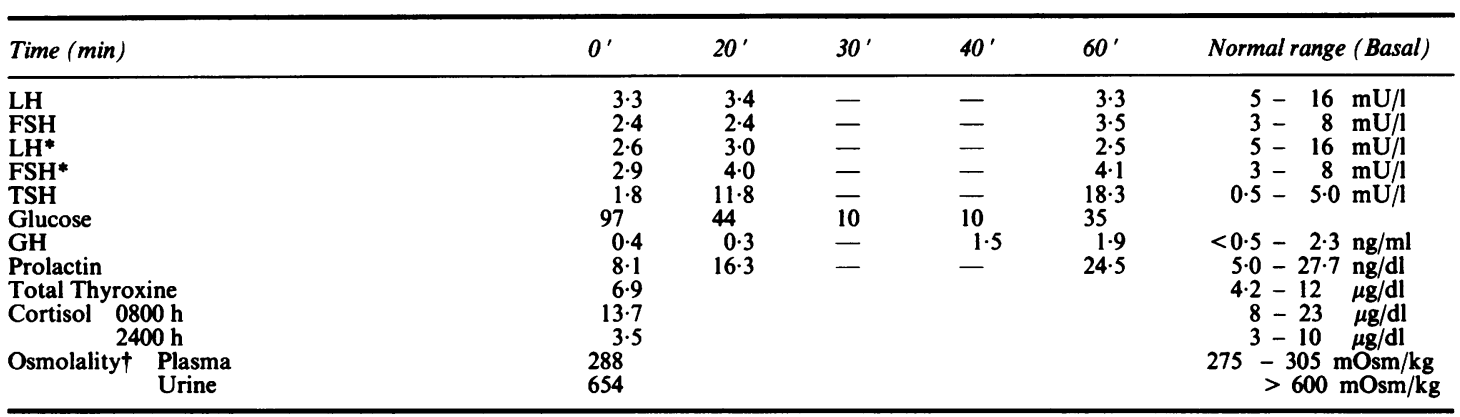

Stimuli used were IV $100 \mu \mathrm{g}$ TRH, $100 \mu \mathrm{g}$ LHRH \& Neutral Insulin 0.1 U/kg body weight.

*Following seven days of twice daily intramuscular $100 \mu \mathrm{g}$ LHRH.

†Samples at $0800 \mathrm{~h}$ following overnight water deprivation. 
marked hypoglycaemia. An intact hypothalamopituitary axis is a pre-requisite for normal $\mathrm{GH}$ release. The impaired response in this patient may be due to a defect in the pituitary or the hypothalamus or both. GHRH stimulation may resolve the issue; poor GH response to GHRH would indicate a defect in the pituitary.

We conclude that the syndrome of ataxia and hypogonadotrophic hypogonadism is not a homogeneous entity. Pituitary deficiency is not isolated to gonadotrophins and there is evidence suggesting hypothalamic dysfunction. It appears that the endocrine disturbance in this syndrome is a spectrum which involves both the hypothalamus and pituitary.

\section{References}

1 Holmes G. A form of familial degeneration of the cerebellum. Brain 1907;30:466-89.

2 Berciano J, Amando JA, Freijanes J, Rebollo M, Vaquero A. Familial cerebellar ataxia and hypogonadotrophic hypogonadism: evidence for hypothalamic LHRH deficiency. J Neurol Neurosurg Psychiatry 1982;45:747-51.

3 Mohr JP. Spinocerebellar degenerations. In: Mohr JP, ed. Manual of Clinical Problems in Neurology. Little, Brown \& Co, Boston, 1984:268-9.
4 Friedreich $\mathbf{N}$. Ueber degenerative atrophie de spinalen hinterstrange. Virchows Arch Path Anat 1863;26:391.

5 Harding AE. Classification of hereditary ataxias and paraplegias. Lancet 1983;i:1151-5.

6 Skre H, Bassoe HH, Berg K, Frovig AG. Cerebellar ataxia and hypergonadotrophic hypogonadism in two kindreds. Chance occurrence, pleiotropism or linkage? Clin Genet 1976;9:234-44.

7 Hecht A, Ruskin H. Seminiferous tubule dysgenesis (Klinefelter's syndrome) associated with familial cerebellar ataxia. J Clinical Endocrinology 1960; 20:1184-90.

8 Indemini M, Amman F. Heredo-degenerescence spinocerebelleuse (HSDC) associée au syndrome de Klinefelter. Confinia Neurologica (Basel) 1963;23: 155-64.

9 Volpe R, Metzler WS, Johnston MW. Familial hypogonadotrophic eunuchoidism with cerebellar ataxia. J Clinical Endocrinology 1963;23:108-15.

10 Boucher BJ, Gibberd FB. Familial ataxia, hypogonadism and retinal degeneration. Acta Neurol Scand 1969; 45:507-10.

11 Vignalou J, Berthaux P, Gouygou Q, et al. Hypogonadisme hypogondotrophique assoc a une maladie de Friedreich. Ann Endocrinol (Paris) 1959;20:172-7.

12 Bernard-Weil E, Endtz L-J. Suruncas familiaal degeneration spinocerebelleuse avec eunuchoidisme hypogonadotrophique. Presse Med 1962;70:524-6. 